Article

\title{
Structuring Ethical Interpretations of the Sustainable Development Goals-Concepts, Implications and Progress
}

\author{
Martina Keitsch \\ Faculty of Architecture and Design, Norwegian University of Science and Technology, 7491 Trondheim, Norway; \\ martina.keitsch@ntnu.no
}

Received: 31 December 2017; Accepted: 10 March 2018; Published: 15 March 2018

\begin{abstract}
The Sustainable Development Goals (SDGs), like the sustainable development (SD) concept itself, are open to multifaceted interpretations, and the same is true for their ethical implications. While SDG values are widely accepted as universal, the ethical structure of the SDGs is complex, with differing interpretations and ideas, e.g., on how to regard and value nature. This article is a conceptual attempt to clarify and structure ethical interpretations based on an environmental ethics framework consisting of two branches: anthropocentrism and biocentrism. The aim is to provide an overview of SDG positions and locate them in the wider field of environmental ethics, addressing the human-nature relationship as a recurring topic in the SDGs. Section 1 of this article presents environmental ethics and briefly discusses anthropocentrism and biocentrism. Section 2 outlines ethical similarities of SD and the SDGs and locates representative SDG interpretations within the environmental ethics framework. Section 3 summarizes findings and suggests a possibility of integrating biocentrism and anthropocentrism with regard to the further interpretation and discussion of SDG ethics. Insights from this article will aid researchers in adopting a better overview on ethical positions in the SDG debate.
\end{abstract}

Keywords: environmental ethics; SDG interpretations; nature experience

\section{Introduction to Environmental Ethics}

The Sustainable Development Goals (SDGs) define a future development agenda for 2015-2030 meant to encourage the international community to move toward a global sustainable future in the next few decades. Against this backdrop, SDG interpretations raise ethical issues in the human-nature relationship directly, in terms of sustainable resource use and/or within the limits of ecosystems [1], or indirectly, in terms of just distribution or equal opportunities [2]. The human-nature relationship is also the focus of interest for environmental ethics.

The following article aims to shed light on some ethical SDG interpretations by analyzing and locating them within an environmental ethics framework. Most of the ethical SDG interpretations refer to anthropocentric positions, but some comprise biocentric or eco-centric aspects. However, the latter often remain implicit. Following the introduction, Section 2 of this article discusses the ethical foundations of anthropocentrism and biocentrism, with a focus on teleological, eudemonistic and virtue ethics. Further, ethical interpretations of SDGs are analyzed with regard to both branches and their subordinated ethical approaches. Section 3 attempts to revisit the biocentric intrinsic value of nature from an anthropocentric perspective and describe it as a social and cultural value. The aim of this attempt is to exemplify and include non-instrumental values of nature in the debate of the SDGs.

The following section briefly introduces ethics, environmental ethics, and the two branches of biocentrism and anthropocentrism. In ethics, one can roughly distinguish between teleological and deontological approaches. The fundamental difference between these elementary moral philosophical 
positions arises among others from their interpretations of morally correct action. Teleological ethics are utilitarianism, eudaemonistic ethics, ethics of responsibility and virtue ethics. They see the "good" as the ultimate goal. Morally correct actions have the maxim: "Act in such a way that the stated (moral) goal is achieved." Deontological ethics such as ethics of duty refer to moral motivation and specific rules, which are independent of the consequences of action, and have the maxim: "Do the good for its own sake" [3].

Historically, questions concerning appropriate behavior toward the environment permeate European culture from Antiquity to Modernity. Noteworthy is Plato's critique of deforestation [4], and Aristotle's classification of animals and humans in the Nicomachean Ethics: "Life is defined in the case of animals by the power of perception in that of man by the power of perception or thought; and a power is defined by reference to the corresponding activity, which is the essential thing; therefore life seems to be essentially the act of perceiving or thinking [5]." Later, e.g., Seneca [6], Agricola [7], and Malthus [8] criticized the human exploitation of nature. Referring to the Greek words "oikos" (house) and "logos" (teaching), Ernst Haeckel introduced the concept of "ecology" as a "science of the natural balance" in 1866 [9].

Even if past centuries are not necessarily depicting a harmonious human-nature relationship, environmental problems had limited geographical impact. This changed with the growing awareness in the 1960s that, besides depleting local ecosystems, accumulated effects of human activities can cause global catastrophes. Carson's "Silent Spring" [10], Ehrlich's "The Population Bomb" [11], and, in particular, the Club of Rome's report "Limits of Growth" [12] are often referred to as being the trigger for contemporary environmental philosophy and ethics. Some authors also claim that the environmental discourse had been fueled by the fact that the exhaustion of natural ecosystems had shown severe consequences not only for nature but also for humans and society itself. Changes in the natural environment placed the social environment under pressure to change [13]. Replying to the increased awareness of a connection between environmental problems and human society, environmental ethics emerged as new and more radical concept of ethics in the early 1970s [14]. Ecological or environmental ethics is a part of bioethics, which also includes medical ethics, animal ethics, gene ethics, and population ethics. It can be understood as a systematic attempt to examine human interventions in ecosystems and nature with regard to ethical justifications and to evaluations of whether prerequisites and consequences of actions are appropriate or not. Systematically, one can roughly differentiate between two environmental ethics branches, biocentrism (including eco-centrism), and anthropocentrism. These two branches diverge fundamentally.

Biocentrism grounds maxims on the intrinsic value of all living beings, while anthropocentrism grounds maxims on human values. The epistemic background for biocentrism is the perception of a biotic community as an interdependent, functioning system. The evolution of life in this system is represented through various forms of living beings, while the simplest forms of beings are still parts of the most complex ones. Even the most complex beings, i.e., humans, cannot exist outside of this system. In this respect, humans are a part of nature; they have not created it but have developed in the same way as all other natural beings in the system. Ethical core values of the biocentric position are the "auto-telos" (self-purpose) and the intrinsic value of living beings. The auto-telos as aim of all living beings to grow and realize their natural purpose is the main argument to constitute their value as moral objects. As moral objects, they have rights, and moral maxims are directed toward them. The main maxim of biocentrism, dependent on which being or system has rights, is that humans have to preserve and protect other living beings, ecosystems, or nature as a whole. Within the overarching ethical framework, one can also distinguish between deontological and teleological positions in biocentrism. Deontic positions justify rights from the pure existence of living beings, ecosystems, or the whole of nature as a reason to prescribe maxims to humans. Teleological positions derive moral obligations from the purposiveness or the interests of living beings, ecosystems, or nature as a whole.

The epistemic background for anthropocentrism is the perception of nature as the human habitat, shaped and maintained according to humans' needs and desires. Nature has to be protected as part of 
the human environment, both for present and future generations. This position implies a hetero-telos (other-purpose, as opposed to self-purpose) of nature and living beings as a basis for teleological or deontological arguments. The maxim to preserve nature and its beings exists only insofar that they have an instrumental value as a resource, or non-instrumental value as objects of contemplative, theoretical, religious, or aesthetic activities.

Teleological anthropocentricism establishes moral action by referring to human interests, while non-rational living beings are assumed to have no interests, desires, and hopes. Their value is assigned to them by humans if they become an object of interest, i.e., are regarded as valuable or as leading to something that is considered valuable. Because of this interest, humans have rights e.g. to use nature resources as effectively and sparingly as possible because resource depletion affects human life quality. Yet, teleological anthropocentricism is different from a pure management strategy, e.g., in its claims for economic viability and social inclusion.

Environmental ethics is a comparatively new field in the history of philosophy, but it has ignited a fundamental debate that affects traditional ethics. The central question for environmental ethics is whether ethics can continue to be anthropocentric, basing rights exclusively on human autonomy, rationality, and the ability to reason, or whether non-human nature can and should be included in ethical considerations-and, if so, how. Recently, moral issues concerning nature's disappearance as an experience and cultural space [15] have become prominent. This implies, epistemologically, an assumed interdependence between socio-cultural and natural surroundings, and, normatively, that this interdependence has a positive value. This value is discussed in more detail in the last section of this article, in the hope that it can contribute toward a more comprehensive understanding of the SDGs. The following section attempts to provide an overview of ethical interpretations of the SDGs and their position in the environmental ethics framework.

\section{Ethical Positioning of SDG Interpretations}

The aims of sustainable development (SD) and their articulation in SDGs advance the discussion on a better world, with emphasis on values for human rights, justice, health, and well-being [16]. Ecological, social and economic developments are considered interrelated [17]. Further, SD and the focus of SDGs both on the human-nature relation, e.g., in SDG12, targets 12.8: "By 2030, ensure that people everywhere have the relevant information and awareness for sustainable development and lifestyles in harmony with nature" [18].

Some authors have stated that sustainable development concerns essentially the human-nature relationship and that SD should be entirely ground on ethics [19]. How far this validates the SDG plan is controversial [20]. The following categorization attempts to clarify some interpretations and to plead to pay more careful attention to their ethical background. For the analysis, a systematic literature search and review [21] was conducted in Scopus and Google Scholar with the following keywords, which are part of the SDGs: "sustainability", "sustainable development", "nature", "resources", "ecosystems", "justice", "culture", and "wellbeing." Other keywords include "SDGs", "biosphere", "ecosphere", "moral values", "ethic(s)", "ethical norms", "morality", and "moral obligations." Keywords were related to each other, e.g., "nature" and "culture", "ecosystem" and "ethics", etc. in order to select relevant articles from the bulk of existing publications. Book chapters and editorials were excluded from the search. The articles were estimated qualitatively by the credibility of the publication channel (peer reviewed). After the review of 68 abstracts, 37 full articles were selected, and 12 of them were kept for analysis. Except for [22], no articles were found that related the SDGs explicitly to environmental ethics. The 12 selected articles exemplify interpretations within the environmental ethics framework rather than provide an overview of existing SDGs literature.

\subsection{Anthropocentric Interpretations}

A comparative perspective on SD and the SDGs allows for an outlining of a common ethical ground. The SDGs are a follow-up plan of sustainable development, which has formed the basic 
concept of the United Nations Conference on Environment and Development held in Rio de Janeiro in 1992 [23]. In 1987, the Brundtland Report [24] had defined sustainable development, as "development that meets the needs of the present without compromising the ability of future generations to meet their own needs."

"Sustainable" denotes "durable." Some authors connect the term is to a human-ecosystem equilibrium [25]. "Development" connotes an assurance to meet human needs. Social injustice may cause as much damage as irresponsible actions toward nature. Justice is therefore an essential value of sustainable development, articulated, e.g., in the inter- and intra-generational part of the definition. The SD Goal 16 with "Justice for all" in Peace, Justice and Strong Institutions [16] also refers to this value.

Both the SD and the SDGs are fundamentally based on anthropocentrism, perceiving nature as human habitat. In anthropocentrism, nature has no intrinsic value or right on its own [16]. Muir expresses this in a classic dispute with Pinchot, a defender of eco-centrism: "Even wilderness and other species had no value for their own sake; they were just human 'resources' to be either exploited through resource extraction or enjoyed for their recreational or esthetic values or to be saved for the enjoyment of future generations of humans" [26]. Ethically, anthropocentrism comprises the maxim that humans should, as far as possible, care for and protect their natural environments.

Several of the analyzed articles can be located within the branch of teleological anthropocentricism, mainly relating to three ethical approaches: ethics of justice, global ethics, and eudemonism. In ethics of justice, rights and duties are based on claims of the intrinsic value of human beings, either religiously grounded or by reference to interest pursuit, reason, self-legislation, and morality. Resulting from these claims are generally valid standards of the equality of rights. Ethics of justice is virtue ethics. Justice relates in the SDG interpretations among others to inclusion and participation. SDG 16 sets the agenda: "Promote peaceful and inclusive societies for sustainable development, provide access to justice for all and build effective, accountable and inclusive institutions at all levels" [16]. Thematizing social justice, the interpretation of Gupta et al. focus, e.g., on including the poor. They analyze "whether the SDG text prioritize the poor and (their) ecological concerns or whether the SDG agenda runs the risk of being hijacked by the ecological and developmental interests of the rich and focus on economic growth at the cost of the other aspects" [2]. Fox's participatory approach refers to human rights as well [27]. He presents participation as an essential element for "more deliberative forms of decision-making" [27].

Both interpretations specify justice as a social and global value and virtue, similar to Rawl's assertion: "Justice is the first virtue of social institutions" [28]. In Fox's analysis, the claim for global justice relates directly to the phenomenon of globalization, affecting social, economic, political, and cultural realms, transcending national borders and prescribing novel ethical rules [27]: "Globalization entails increasing levels of interdependence, leading to a corresponding erosion of national sovereignty." From a philosophical perspective, Iris Marion Young argues that the scope of a polity should extend as wide as the scope of social and economic interactions that raise issues of justice, which in today's context "implies the need for global democratic institutions" [27,29].

From a historical perspective, Apel was one of the first authors who connected global development, justice, and responsibility, aiming to identify what they entail on a global scale. When Apel coined the notion "Macroethics" in 1990 [30], he was referring to human-nature relationship, assuming that accumulated human activities can damage the environment globally. Because of the collective character of their actions, humans should also share a joined responsibility. Macroethics aims at realizing the interconnectedness of actions in different societal sectors. The duty of actors in these sectors is giving reasonable arguments for collective actions: "The most difficult problem in this context appears to be changing our scientific technology and our market based economic system in such a way that their efficiency and power of motivation are not destroyed but rather put into service of a sustainable way of human life" [31]. In 1994, Pogge developed an institutional global theory of justice, based on the wealth gap between rich and poor, which is causing structural injustices. Pogge's theory ascribes a moral responsibility of the global rich at least not to harm [32]. "If the global economic order plays a 
major role in the persistence of severe poverty worldwide and if our governments, acting in our name, are prominently involved in shaping and upholding this order, then the deprivation of the distant needy may well engage not merely positive duties to assist but also more stringent negative duties not to harm" [33].

Referring to structural social justice, responsibility of governments and international organizations is discussed similarly in terms of current SDG interpretations [34]. Fukuda-Parr et al. assert, e.g., that today's global economic system is unfair, because the rich simultaneously benefit from it and sustain it. Within this system, international organizations make and maintain policies for marginalized and poor citizens and countries. This gives these organizations a special power and related responsibility. Fukuda-Parr et al. assume, however, that this responsibility is unlikely to be realized under present circumstances and find current concepts of responsibility "simply outdated [since they are] a reflection of issues that derive from, and are most suited to, issues of smaller scale interaction" [34]. Without being too specific about which kind of concepts of responsibility are outdated and why this is the case, the authors state further that a new, political responsibility is required: "Political responsibility with respect to structural injustice often requires transforming of institutions and the tasks they assign" [34]. The authors are not defining political responsibility and their claim culminates in a ubiquitous conclusion: "This is everyone's task and no one's in particular, and, furthermore, it is a shared task; it implies that individuals reconsider their own responsibilities" [34].

The recourse to the individual person is a surprising turn in this interpretation. One expects rather that responsibility should move forward and outward to become political responsibility, ethically reflected for example in Kohlberg's ethics [35], which transgresses from individual self-interest via conventional societal interest to universal ethical interest and principles. Fukuda-Parr et al. realize this dilemma. They state that common-sense morality has limitations and again pronounce "institutional responsibility as an alternative" [34]. Within this context, they refer to the adoption of the Millennium Declaration by world leaders, which allowed for the systematic monitoring of implementation with the help of indicators, and where results could be compared across countries and time. Their recommendation is that lessons learned through the Millennium Development Goals (MDGs) should be integrated the SDGs. Further, scholarly communities, communities of practice and social movements should be mobilized to ensure responsibility and accountability in implementing the SDGs.

Bexell et al. specify the concept of responsibility in relation to global social justice. They present responsibility within a typology of cause, obligation, and accountability [36]: "In the first sense, responsibility means a claim that someone or something caused an outcome without necessarily implying that the individual, thing or organization causing it will have to answer in any way for the outcome" [36]. The article provides a useful explanation of responsibility, even if it is not clear if its definition originates from the authors or to whom they refer. The "contribution principle" [36] is applied to structural processes, where it creates responsible obligations for those producing injustice, and maybe even more so if this is on a global scale. Considering the SDGs in terms of cause and obligation means investigating "the role of historical legacies for present obligations." Responsibility in the sense of obligation implies undertaking specific tasks in a forward-looking meaning and relates structurally to "the collective action of institutions, which have greater capacities for addressing structural conditions than do individuals" [36]. Accountability refers to explaining former decisions and behavior on all scales individually and collectively. "In the case of accountability, researchers should continue examining the development of SDG review processes nationally and internationally with an eye to what agents are held accountable, for what and to whom" [36].

Eudemonism defines ethical action as leading to the wellbeing, happiness, or the good life of an individual as essential values. This is not only referring to favorable material and social conditions, but also to spiritual and mental contentment. The crucial goal of society is to facilitate a good and happy life for its individuals. A reference to eudemonism is in SDG 3: "Ensure healthy lives and promote well-being for all at all ages" [17]. SDG interpretations above consider social wellbeing or 
wellbeing of the poor in relation to justice. They refer to physical and social wellbeing in general terms. No articles on well-being as relating to pleasure, experiences, and self-realization were found. No articles on factual differences of living conditions and expectations, which play an important role in describing wellbeing, were found. An investigation and discussion of different forms of the wellbeing and the "good life" within contextualized cultural and social settings seems, however, desirable to supplement general statements and prevent the manifestation of a Western dogmata of wellbeing in the SDG debate. This investigation and discussion may include if and how nature can be regarded and protected as a source of wellbeing (and health).

\subsection{Biocentric Interpretations}

The human-nature relationship remains underrated in anthropocentric SDG interpretations in contrast biocentric interpretations. Classical biocentrism refers to nature's ontological status and grounds human duties toward the environment on nature's intrinsic value. Biocentrically inspired SDG interpretations justify ethical claims epistemologically by arguing that assertions are consistent with a particular theory [37], often implying incorrect appeals to ecological science [1]. Brandi argues, for example, that: "the new set of SDGs should ensure that human societies operate within the safe operating space defined by planetary boundaries" [1]. She refers to occurrences that cause ecological threats, such as "climate change, biodiversity loss, interference with the nitrogen and phosphorus cycles, stratospheric ozone depletion, ocean acidification, global freshwater use, changes in land use, chemical pollution and atmospheric aerosol loading, out of which three have by now reached a critical state with the boundaries for climate, nitrogen and biodiversity already having been crossed" [1]. Consequently, ethical recommendations originate from the state of the environment: "The concept of planetary boundaries or guard rails $[\ldots]$ can and should provide the basis for a new approach to global ethics" [1].

The dilemma that humans and nature appear as both interdependent and separated from each other is often ignored in these interpretations. While the anthropocene poses fundamental challenges to society, moral practice seems also be a part of human phylogenetic development, expressed, e.g., in the statement: "The 'Earth system SDG' reminds us to focus our attention on inequality" [1]. The antinomy of humans as part or apart from the environment has been widely discussed in philosophy (e.g., in Heidegger's and Næss' ontological ethics). One criticism against the former is that nature, as a model for ethics, cannot explain specific human characteristics in the moral dimension. Pichler et al. explain, for example, that emancipation from nature created separation. This separation made it possible for humans to develop abilities that are not intrinsic in the natural, phylogenetic process: "With the Neolithic revolution and the beginning of agricultural production, the Earth's surface was altered through deforestation, land cultivation, and the expansion of human settlements." One can argue how far these abilities are useful to protect the planet and life. This discussion relates, however, to practical, theoretical, and communicative reasoning for or against usefulness, not to human nature and its immanent emancipatory potential. Similarly, nature can be a main dimension of environmental, ethical discourses, but it cannot determine their normative fundament.

A common characteristic of the biocentric interpretations is that notions such as "system", balance", "boundary", "homeostasis", etc. are normatively connoted. This is presented, e.g., in Pichler et al.: "Based on an in-depth understanding of society-nature relations, conclusions for sustainability transformations can be drawn that go far beyond the postulated need for 'Earth System governance', that is, 'societal steering of human activities with regard to the long-term stability of geobiophysical systems'" [38]. These notions become, however, metaphysical when exceeding the ecological definition. If they do not, they cannot become normative. In some interpretations, a systems metaphor is used to describe the human-nature relationship and sometimes it culminates into an all-encompassing analogy: "Societies reshape their environment in order to obtain material and energy inputs and to discharge waste and emissions, that is, to maintain their social metabolism" [38]. 
This assertion is resembles the "anthropomorphia inversa" in biologism, projecting social phenomena to the animal realm and reversing them as "quasi-natural" behavior back to humans [3].

Overall, most biocentric interpretations adhere to a "learning-from-nature" paradigm. In some concepts, nature seems to play the role of a moral guideline. Considering the arguments above, it remains nevertheless difficult to justify ethical claims with, e.g., Earth system science, planet boundaries, or similar ideas. Biocentric SDGs approaches are also limited in their interpretations of socio-ecological "systems" interactions and often consider only resource aspects of nature. Most of the biocentric interpretations discussed here can be classified as teleological ethics.

\section{Conclusions: Moderate Biocentrism and the SDGs}

The biocentric and ecocentric SDG interpretations discussed in this article display a need for ethical justification. Nevertheless, from the author's point of view, they contain important values for the SDG ethics debate. Currently, the SDGs and many interpretations see nature in the human-nature relationship from a mere instrumental point of view. Kopina is an exception in this sense. She discusses the role of neglected and disadvantaged stakeholders in the SDG debate, including nature as a "third party." Kopina's interpretation is highly normative, promoting for example anti-capitalist views to protect the "victims of unsustainability", advocating "an invocation of ethical duty toward environment and its elements" [22] or fronting a claim for unity: "[W]e have to be on the same page and speak of the same meaning. In a finite world, we need to accept once and for all that sustainability cannot be about further growth. This challenge remains critical, though still denied" [22]. Further, she criticizes injustice between species, the commodification of nature and privileging human well-being [38]. While nature is objectified in the other SDG interpretations, Kopina refers to feelings and experiences in the human-nature relationship and claims that moral obligations resonate from intuitive understanding of these values: "Basic human moral obligations to uphold the values basic to life-life itself, its sanctity and dignity and the values which maintain such a life" [39].

It is logically impossible to derive ethical guidelines from nature. Ethics relates sui generis to human values. However, exploring natural system characteristics such as interdependence, diversity, complexity, and their affiliation and differentiation from social values such as responsibility, openness, and correspondence can help one to integrate biocentric and anthropocentric ideas for the benefit of SDGs [3]. For example, diversity denotes the dissimilarity of components in system theory. In an ecosystem, diversity comprises, e.g., the variety of existing species, the physical characteristics of the milieu, and the interactions between both. An ethical connotation of diversity can address recognition and appreciation of multiple cultures and of perspectives from various stakeholders.

Several of the SDGs and their ethical interpretations have the human-nature relationship as a common denominator for discussion. Similarly, biocentrists and anthropocentrists agree on this relationship as a focus for ethical reflections. A convincing argument in this debate is that values assigned to nature are values defined by humans. Biocentrism, with its idea of a presupposed nature, is not reflecting this argument. This does not mean that the "intrinsic" value of nature has no conceptual significance. It means that natures self-value is actually inherent, it is a human-constituted value, and as such it relates not to ecology or biology but to society and culture. Heuristically, assuming an intrinsic value of nature has an ethical value for these domains among other related concepts of "autonomy" and "non-instrumentality" and for seeing humans as natural, physical beings [40].

The existence of nature as a space and possibility for experience is another socio-cultural value. As a socio-cultural value, nature experience relates, e.g., to wellbeing and life quality. Ethically, it can work as a regulative in the SDG debate, currently overly dominated by instrumental rationality toward nature. Thereby, the value of nature experience can support the constitutive SDGs ethically in at least three aspects. First, nature experience transcends material aspects of nature, for example, through correspondence with other beings. From an ethical point of view, correspondence can evoke empathy and compassion. Justice is a rational concept, while empathy can contribute to an improvement in environmental attitudes and practices [3]. Second, on a personal and socio-cultural 
level, an appreciation of place and cultural identity relate partly to natural surroundings. This means that nature experience is a part of culture in a life-worldly, bodily, and daily sense [15], and both culture and nature contribute to a common horizon and reference frame. Nature experience connects here to concepts of "home" and "belonging"-love and attachment to specific surroundings. Third, from an epistemological perspective, introducing the subjective experience of a desirable nature, regarding humans as individual beings [41] would open the SDG debate for communicative arguments [42] additionally to purposive rational arguments.

Conclusively, the SDGs are a reasonable contribution to pragmatize the SD discourse. However, to be a valid followup of the SD concept, the SDG plan requires a continuous inspection of attitudes and values. Robin explains: "Sustainability [ . . ] is itself the emergent property of a conversation about what kind of world we collectively want to live in now and in the future" [43] Ethical interpretations in this conversation have thus far related to nature as a resource for knowledge and actions. Readings of nature as a source and value for experience remain to be investigated.

Conflicts of Interest: The authors declare no conflict of interest.

\section{References}

1. Brandi, C. Safeguarding the earth system as a priority for sustainable development and global ethics: The need for an earth system SDG. J. Glob. Ethics 2015, 11, 32-36. [CrossRef]

2. Gupta, J.; Vegelin, C. Sustainable development goals and inclusive development. Int. Environ. Agreement. 2016, 16, 433-448. [CrossRef]

3. Keitsch, M. Naturästhetik und Ökologische Ethik: Eine Einführung; Verlag Dr. Kovac: Hamburg, Germany, 2003.

4. Plato. Critias. Translated by Benjamin Jowett. Available online: http://classics.mit.edu/Plato/critias.html (accessed on 24 February 2018).

5. Aristotle, Nicomachean Ethics. Chapter 9, Section 9. Available online: http:/ / classics.mit.edu/Aristotle/ nicomachaen.9.ix.html (accessed on 24 February 2018).

6. Seneca, the Younger. Moral Letters to Lucilius. Letter 90. Available online: https://en.wikisource.org/wiki/ Moral_letters_to_Lucilius/Letter_90 (accessed on 24 February 2018).

7. Agricola, G. De Re Metallica, e.g., p. 67. Available online: http://archimedes.mpiwg-berlin.mpg.de/ docuserver/images/archimedes/agric_remet_002_en/downloads/agric_remet_002_en.text.pdf (accessed on 24 February 2018).

8. Malthus, T. An Essay on the Principle of Population. Available online: http://www.esp.org/books/malthus / population/malthus.pdf (accessed on 24 February 2018).

9. Haeckel, E. The History of Creation. Available online: https://archive.org/stream/historyofcreatio76hist\# page/n0/mode/2up (accessed on 14 March 2018).

10. Carson, R. Silent Spring; Mariner Books: Boston, MA, USA, 2002.

11. Ehrlich, P. The Population Bomb. Available online: http://projectavalon.net/The_Population_Bomb_Paul_ Ehrlich.pdf (accessed on 24 February 2018).

12. Meadows, D.; Meadows, D.; Randers, J.; Behrens, W.W., III. The Limits to Growth. A Report for the Club of Rome's Project on the Predicament of Mankind. Available online: http:/ /www.donellameadows.org/wpcontent/userfiles/Limits-to-Growth-digital-scan-version.pdf (accessed on 24 February 2018).

13. Odum, E.P. Ecology: A Bridge between Science and Society; Sinauer Associates Publishers: Sunderland, MA, USA, 1998.

14. Environmental Ethics. Available online: https://plato.stanford.edu/entries/ethics-environmental/ (accessed on 24 February 2018).

15. Seghezzo, L. The five dimensions of sustainability. J. Environ. Politics 2009, 18, 539-556. [CrossRef]

16. SDG 16: Peace, Justice and Strong Institutions. Available online: http://www.undp.org/content/undp/ en/home/sustainable-development-goals/goal-16-peace-justice-and-strong-institutions.html (accessed on 24 February 2018).

17. SGD 3: Good Health and Wellbeing. Available online: http://www.undp.org/content/undp/en/home/ sustainable-development-goals/goal-3-good-health-and-well-being.html (accessed on 24 February 2018). 
18. SDG 12, 12.8: Sustainable Production and Consumption. Available online: http://www.undp.org/content/ undp/en/home/sustainable-development-goals/goal-12-responsible-consumption-and-production/ targets.html (accessed on 24 February 2018).

19. Nelson, M.; Vucetich, J. Sustainability Science: Ethical Foundations and Emerging Challenges. Nat. Educ. Knowl. 2012, 3, 12.

20. McIntyre, M. The inescapably ethical foundation of sustainability. Int. J. Busi. Gov. Ethics 2017, 12, 127-150. [CrossRef]

21. Yin, R.K. Case Study Research: Design and Methods, 3rd ed.; Sage: Thousand Oaks, CA, USA, 2003.

22. Kopnina, H. The victims of unsustainability: A challenge to sustainable development goals. Int. J. Sustain. Dev. World Ecol. 2015, 23, 113-121. [CrossRef]

23. What Is Sustainable Development? Available online: http://www.sd-commission.org.uk/pages/history_sd. html (accessed on 24 February 2018).

24. World Commission on Environment and Development. In Our Common Future; Oxford University Press: Oxford, UK, 1987.

25. Shaker, R. The spatial distribution of development in Europe and its underlying sustainability correlations. Appl. Geogr. 2005, 63, 304-314. [CrossRef]

26. Muir, J. Deep Ecology for the Twenty-First Century; Sessions, G., Ed.; Oxford University Press: Shambala, UK, 1995.

27. Fox, O.; Stoett, P. Citizen Participation in the UN Sustainable Development Goals Consultation Process: Toward Global Democratic Governance? Glob. Gov. 2016, 22, 555-574.

28. Rawls, J. A Theory of Justice; Harvard University Press: Cambridge, MA, USA, 1971; p. 3.

29. Collste, G. Globalisation and Global Justice-A Thematic Introduction De Ethica. J. Philos. Theol. Appl. Ethics 2016, 3, 5-7. [CrossRef]

30. Apel, K.O. The Problem of a Universalistic Macroethics of Co- responsibility. In What Right Does Ethics Have? Public Philosophy in a Pluralistic Culture; Griffioen, S., Ed.; VU University Press: Amsterdam, The Netherlands, 1990; pp. 23-40.

31. Apel, K.-O. The ecological crisis as a problem for discourse ethics. In Proceedings of the Melbu Conference, Melbu, Norway, 18-23 July 1990; pp. 219-260.

32. Pogge, T. An Egalitarian Law of Peoples. Philos. Public Affairs. 1994, 23, 195-224. [CrossRef]

33. Pogge, T. “Assisting” the Global Poor. Page 5. Available online: http://www.princeton.edu/rpds/seminars / pdfs/pogge_assistingpoor.pdf (accessed on 21 December 2017).

34. Fukuda-Parr, S.; McNeill, D. Post 2015: A new era of accountability? J. Global Ethics 2015, 11, 10-17. [CrossRef]

35. Kohlberg, L. The Claim to Moral Adequacy of a Highest Stage of Moral Judgment. J. Philos. Available online: https:/ / philpapers.org/rec/KOHTCT (31 December 2017).

36. Bexell, M.; Jönsson, K. Responsibility and the United Nations' Sustainable Development Goals. Forum Dev. Stud. 2017, 44, 13-29.

37. Shrader-Frechette, K. Practical Ecology and Foundations for Environmental Ethics. J. Philos. 1995, XCII, 621-635.

38. Pichler, M.; Schaffartzik, A.; Haberl, H.; Görg, C. Drivers of society-nature relations in the Anthropocene and their implications for sustainability transformations. Curr. Opin. Environ. Sustain. 2017, 26-27, 32-36. [CrossRef]

39. Motilal, S. Sustainable development goals and human moral obligations: The ends and means relation. J. Glob. Ethics 2015, 11, 24-31. [CrossRef]

40. Keitsch, M. Some Perspectives on Environmental Ethics, Parabel, Tidsskrift for Filosofi og Vitenskapsteori; Tapir forlag: Trondheim, Norway, 2002.

41. Berenguer, J. The Effect of Empathy in Proenvironmental Attitudes and Behaviors. Environ. Behav. 2007, 39, 269-283. [CrossRef]

42. Seel, M. Eine Ästhetik der Natur; Suhrkamp Frankfurt/M: Berlin, Germany, 1991.

43. Habermas, J. Between Facts and Norms. In Contributions to a Discourse Theory of Law and Democracy; MIT Press: Cambridge, MA, USA, 1996.

(C) 2018 by the author. Licensee MDPI, Basel, Switzerland. This article is an open access article distributed under the terms and conditions of the Creative Commons Attribution (CC BY) license (http:/ / creativecommons.org/licenses/by/4.0/). 